\title{
BMJ Open Influence of childcare practices on nutritional status of Ghanaian children: a regression analysis of the Ghana Demographic and Health Surveys
}

\author{
Dickson A Amugsi, ${ }^{1}$ Maurice B Mittelmark, ${ }^{1}$ Anna Lartey,${ }^{2}$ Dennis J Matanda, ${ }^{1}$ \\ Helga B Urke ${ }^{1}$
}

To cite: Amugsi DA, Mittelmark MB, Lartey A, et al. Influence of childcare practices on nutritional status of Ghanaian children: a regression analysis of the Ghana Demographic and Health Surveys. BMJ Open 2014:4:e005340.

doi:10.1136/bmjopen-2014005340

- Prepublication history for this paper is available online. To view these files please visit the journal online (http://dx.doi.org/10.1136/ bmjopen-2014-005340).

Received 25 March 2014 Revised 9 September 2014 Accepted 11 September 2014

CrossMark

\begin{abstract}
${ }^{1}$ Department of Health
Promotion and Development, University of Bergen, Bergen, Hordaland, Norway

${ }^{2}$ Nutrition Division, Economic and Social Department, Food and Agriculture Organization, Rome, Italy
\end{abstract}

Correspondence to Dickson A Amugsi; damugsi2002@yahoo.com

\section{ABSTRACT}

Objectives: Guided by the UNICEF framework for childcare, this study examined the association of childcare practices (CCP) with infant and young children's growth (height-for-age Z-scores, HAZ), and investigated whether care practices are more important to growth in some sociodemographic subgroups of children.

Design: Cross-sectional survey.

Setting: Urban and rural Ghana.

Participants: The study sample comprised 1187 dyads of mothers aged 15-49 years and their youngest child (aged 6-36 months).

Results: The results showed that CCP was a significant predictor of $\mathrm{HAZ}$, after controlling for covariates/confounders at child, maternal and household levels. Children with higher CCP scores had higher HAZ. A 1-unit increase in the CCP score was associated with a 0.17 -unit increase in HAZ. Child's and mother's age, number of children under 5 years, place of residence, maternal weight and wealth index were also significantly associated with HAZ. Statistical interaction analyses revealed no subgroup differences in the CCP/HAZ relationship.

Conclusions: This study found a significant, positive association between CCP and child growth, after accounting for other important determinants of child growth at maternal and household levels. This calls for research into the effects on growth of various CCP components, with longitudinal cohort study designs that can disentangle causal relationships.

\section{INTRODUCTION}

The foundational UNICEF framework for child health emphasises that childcare practices (CCP) are vitally important in promoting child nutrition and health. ${ }^{1}$ Sociodemographic factors (eg, parental education and income) are also emphasised in the UNICEF framework, and are consistently found to have a graded relationship with health. ${ }^{2}$ However, little is known about the degree to which CCP
Strengths and limitations of this study

- Use of a high-quality nationally representative sample to investigate the relationship between childcare practices and nutritional outcomes.

- Creation of a composite childcare measure including home care and medical care dimensions.

- Data from cross-sectional survey, while longitudinal data would have been preferred.

- Lack of variables to measure cultural, sociopolitical and locality influences on child health.

are consistently related to child health in the face of the widely differing sociodemographic backgrounds that characterise societies.

Childcare is a complex concept including a range of behaviours and practices of caregivers that provide the food, healthcare, stimulation, and emotional support necessary for children's healthy survival, growth and development. ${ }^{3}$ As part of CCP, feeding and healthcare underlie dietary sufficiency and protection from disease, which in turn impacts child health, for which physical growth is a critical marker. ${ }^{4}$

A robust finding in public health research is that of a graded relationship between sociodemographic status (SDS) and health. ${ }^{5}$ Low SDS translates predictably into lessened food security and reduced access to healthcare. However, even in households with food insecurity due to poverty and poor access to healthcare, families can optimise the use of the existing resources to promote health. ${ }^{36}$ This calls for further research to illuminate the relationship between childcare and child health in economically vulnerable as well as secure households and communities. An ecological approach to such research calls for specification of proximal influences on child health such as feeding practices, as well as consideration of more distal factors such as 
caregivers' health literacy, availability of resources such as clean water and sanitary living conditions and accessible healthcare. ${ }^{7}$

In the Global South, ${ }^{\mathrm{i}}$ interventions to reduce child undernutrition focus often on household food security (adequacy of food availability), without taking into consideration the complementary role of quality childcare. This can be seen in most of the nutrition intervention programmes in Ghana. ${ }^{8}$ Yet food security alone is not enough to improve children's nutritional status, and the significance of care practices to improving children's nutritional status has been documented repeatedly. ${ }^{6-16}$ Despite the fact that quality of childcare has a demonstrated role in alleviating child undernutrition in resource-constrained settings such as Ghana, there have been only two Ghanaian studies (of which we are aware) that have examined the role of childcare in relation to children's nutritional status. The pioneering study of Ruel $e t a t^{6}$ in urban Accra used a composite care practices variable (care practice index) to examine the importance of care for healthy child nutrition. The other study, by Nti and Lartey, ${ }^{16}$ was conducted in one rural area; both studies found a significant association between care practices and children's nutritional status. However, the setting specificity of these two studies limits the generalisability of their findings. Addressing this limitation, this paper presents an analysis of the relationship between care practices and children's nutritional status in Ghana, using a national representative sample. The primary objective of this analysis was to examine the influence of CCP on children's height-for-age Z-scores (HAZ), controlling for covariates and potentially confounding factors at child, maternal, household and community levels. The secondary objective was to establish whether care practices were more important to growth in some sociodemographic subgroups of children compared with others.

\section{METHODS}

\section{Data sources}

The Ghana Demographic and Health Survey (DHS) data collected in 2008 were used for the analysis. These data are in the public domain and available from the MEASURE DHS website. ${ }^{17}$ The Ghana Statistical Service and the Ghana Health Service collected the data, using the 2000 national population census as a sampling frame.

The participants were 1187 children aged 6-36 months (393 urban and 794 rural) from whom anthropometry

\footnotetext{
'By 'Global South' we refer to parts of the world that are also termed 'the third world' and 'developing countries' (which may carry pejorative connotations). The Global South is a geopolitical concept including parts of the world located notably in the Equatorial Zone that have colonial pasts, challenging geopolitical conditions, and that are rising in economic, social and political resilience. Regions not having these conditions are of course found outside the Equatorial Zone.
}

data were obtained. This excluded 224 children in the survey from whom complete and in-range anthropometry data could not be obtained. The weight measurements were undertaken using electronic Seca scales. Height measurements were obtained using a measuring board. Children younger than 24 months were measured lying on the board, while standing height was measured for older children. ${ }^{18}$

\section{Outcome variable}

The outcome variable for this analysis was HAZ.

\section{CCP measurement}

The variables used in creating the CCP score were feeding practices variables and use of preventive health service. The feeding practices variables included dietary diversity score (DDS), which was created using 16 food groups: (1) tinned/powder or fresh milk; (2) baby formula; (3) baby cereal; (4) bread, rice, noodles, other made from grains; (5) potatoes, cassava or other tubers; (6) eggs; (7) meat (beef, pork, lamb, goat, chicken, etc.); (8) dark green leafy vegetables; (9) mangoes, papayas, other vitamin A fruits; (10) other fruits; (11) pumpkin, carrots, squash (yellow or orange inside); (12) liver, kidney, heart, other organs; (13) fish or shellfish (fresh or dried); (14) food made from beans, peas, lentils, nuts; (15) oils, fats, butter, products made from them; (16) cheese, yogurt, other milk products. Details about the DDS are presented elsewhere. ${ }^{19}$ Other feeding variables were frequency of feeding solid or semisolid food and breast feeding status. The preventive health service variables included: BCG vaccination, DPT, hepatitis $\mathrm{B}$, influenza, polio and measles vaccinations, iron supplementation, and use of drugs for intestinal parasites.

The CCP score was created using the results of Principal Component Analysis. ${ }^{20-22}$ We employed the regression method, with component loadings adjusted to account for the correlations between variables, and used the oblique factor rotation procedure. Component extraction was based on eigenvalues $>1$, and four principal components were extracted that explained $70 \%$ of the variance. No item had a loading less than $0.4 .^{20}$ Therefore, all the items were used to create the composite care practices score, treated in subsequent analyses as a continuous variable.

\section{Other variables used in the analysis:}

A. maternal age, height, weight, number of antenatal care (ANC) visits education, occupation, anaemia level and parity;

B. method of disposal of the youngest child's stool;

C. empowerment variables including women's role in household decision-making, opinion regarding wife beating, and attitudes regarding sexual relations with husband;

D. household-level variables including the number of children under 5 years in the household, Wealth 
Index (WI), urban/rural place of residence, source of drinking water, religion and type of toilet facilities;

E. the child-level variables sex and age (child's age was transformed into age squared and included in regression analyses to account for non-linearity of the age variable. $^{23}$

Some of the variables were recoded. Source of drinking water and toilet facilities were recoded according to the WHO and UNICEF $^{24}$ recommended classifications: 'improved' and 'unimproved' water and 'improved' and 'unimproved' sanitation facilities. The disposal of the youngest child's stool was recoded into 'appropriate' and 'inappropriate' disposal methods. Maternal occupation was recoded into 'white collar' and 'agriculture/ labour', and religion into 'Christians' and 'other religions'. For the empowerment variables, three indices were created based on the $\mathrm{DHS}^{18}$ recommended procedure (participation in household decision-making, opinion regarding wife beating, and justified to refuse sexual intercourse with husband). High scores were coded 'more empowered' and low scores 'less empowered'. The wife beating attitude variable was reverse coded so that a high score corresponded to being more empowered.

\section{Analytical framework and methods}

This analysis is framed using the UNICEF conceptual framework in which food, health and care are posited as the three key pillars influencing child survival, growth and development. ${ }^{1}$ The model identifies three levels of causes of child undernutrition: immediate (operating at the individual level), underlying (influencing household and communities) and basic causes (structure and processes of societies). The model suggests that these causal factors affect a child's nutritional status in a chain-like manner-the basic factors affect the underlying factors, which in turn affect the immediate factors, in turn affecting the child's nutrition status. The model was extended by Engle $e t a l^{25}$ and the above levels reclassified broadly as context, resources and caregiving. This analysis used this framework to structure the hierarchical multiple regression analyses.

The General Linear Model (GLM) in the SPSS 21 Complex Samples command was used to perform the multivariate analysis. The GLM was used to allow adjustment for survey design effects (sample weight, strata and cluster). The analysis involved four steps. The first step (model A) contained only the basic characteristics of the mother (age) and child (age and sex), to examine the direct effects of these factors on HAZ. The second step (model B) introduced context variables (place of residence and religion) in the model in the presence of the basic factors to establish how the context variables were directly related to HAZ. The third step (model C) introduces resource variables (education, occupation, anaemia level, parity, disposal of the youngest child's stool, household decision-making, opinion regarding wife beating, justified to refuse sexual intercourse with husband, number of children under 5 years, WI, source of drinking water, type of toilet facilities), controlling for basic and contextual factors. In the final step (model D), the CCP score was introduced, controlling for basic, contextual and resource factors. Tests of interactions between the CCP score and other predictor variables were undertaken, because previous research has documented that children from poorer households and/or those of mothers with less education may be more likely to benefit more from better care practices, compared with children of wealthier households or those of mothers with better education. ${ }^{6}$

\section{RESULTS}

\section{Characteristics of the sample}

Tables 1 and 2 present the descriptive statistics of the sample. The average age of children used in the analysis was about 20 months. The mean HAZ for the sample was $-1.09 \quad(\mathrm{SD}=1.7)$, while the weight-for-age and weight-for-height Z-scores, respectively, were -0.81 $(\mathrm{SD}=1.3)$ and $-0.33(\mathrm{SD}=1.5)$. The average prevalence of stunting, underweight and wasting was $29.1 \%, 16.0 \%$ and $11.5 \%$, respectively. The average age of the mothers was 28 years. The number of ANC visits was relatively low (1.74 visits). Breast feeding was generally above average in this population $(67 \%)$. The average frequency of feeding the child with solid or semisolid food within $24 \mathrm{~h}$ was 2.59 . Immunisation rates were high among this population. BCG, which is given at birth, was as high as $94 \%$. Additionally, $87.7 \%$ of children older than three months had received all their DPT vaccination and $85.6 \%$ received polio 3 vaccinations. For children older than 9 months, $86.7 \%$ received their measles vaccination. Fewer children in the sample received iron supplement $(29.0 \%)$. The use of drugs for intestinal parasites was low $(37.2 \%)$, probably because the children in the sample were relatively young. With regard to water and

Table 1 Characteristics of the sample $(\mathrm{N}=1187)$, continuous variables

\begin{tabular}{lcc}
\hline Variables & Mean & SD \\
\hline Child's age & 19.8 & 8.55 \\
Child's HAZ & -1.09 & 1.72 \\
Child's WAZ & -0.81 & 1.3 \\
Child's WHZ & -0.33 & 1.49 \\
Maternal age (years) & 28.18 & 6.77 \\
Maternal height (cm) & 1.59 & 0.07 \\
Maternal weight (cm) & 58.17 & 10.83 \\
Number of children U5 in household & 1.88 & 1.00 \\
Number of ANC visits & 1.74 & 0.53 \\
Number of times the child ate solid, & 2.59 & 1.32 \\
semisolid or soft food previous day & & \\
Dietary diversity score for child & 5.92 & 3.06 \\
\hline ANC, antenatal care; HAZ, height-for-age Z-scores; WAZ, \\
weight-for-age Z-scores; WHZ, weight-for-height Z-scores; U5, \\
under 5 years. & &
\end{tabular}


Table 2 Characteristics of the sample $(\mathrm{N}=1187)$, categorical variables

\begin{tabular}{|c|c|c|}
\hline Characteristics & $\mathbf{N}$ & (Per cent) \\
\hline \multicolumn{3}{|l|}{ Sex of child } \\
\hline Male & 600 & 50.5 \\
\hline Female & 587 & 49.5 \\
\hline Still breast feeding (yes) & 797 & 67.1 \\
\hline \multicolumn{3}{|l|}{ Use of preventive health service } \\
\hline Received BCG (yes) & 1120 & 94.5 \\
\hline Received DPT/hepatitis B/influenza 3 (yes) & 1037 & 87.7 \\
\hline Received polio 3 (yes) & 1013 & 85.6 \\
\hline Received measles $\geq 9$ months (yes) & 927 & 86.7 \\
\hline Taking iron pills, sprinkles or syrup (last 7 days; yes) & 343 & 29.0 \\
\hline Drugs for intestinal parasites (yes) & 438 & 37.2 \\
\hline Anaemia level (some anaemia) & 718 & 61.5 \\
\hline \multicolumn{3}{|l|}{ Empowerment } \\
\hline \multicolumn{3}{|l|}{ Participation in decision-making } \\
\hline Low participation & 343 & 28.9 \\
\hline \multicolumn{3}{|l|}{ Husband justified in beating wife } \\
\hline Less sense of empowerment & 267 & 23.1 \\
\hline \multicolumn{3}{|l|}{ Wife justified in refusing sex } \\
\hline Less empowered & 173 & 15.1 \\
\hline \multicolumn{3}{|l|}{ Water and sanitation } \\
\hline \multicolumn{3}{|l|}{ Source of drinking water } \\
\hline Unimproved & 262 & 22.2 \\
\hline \multicolumn{3}{|l|}{ Type of toilet facilities } \\
\hline Unimproved & 557 & 47.3 \\
\hline \multicolumn{3}{|l|}{ Disposal of the youngest child's stool } \\
\hline Inappropriate disposal practice & 740 & 62.6 \\
\hline \multicolumn{3}{|l|}{ Religion } \\
\hline Christian & 802 & 67.7 \\
\hline Other religions & 383 & 32.3 \\
\hline \multicolumn{3}{|l|}{ Place of residence } \\
\hline Urban & 394 & 33.1 \\
\hline Rural & 793 & 66.9 \\
\hline
\end{tabular}

sanitation, 22.2\% of this population did not have access to improved source of water and $47 \%$ used unimproved sanitation facilities. Also, a high proportion of mothers $(63 \%)$ used inappropriate ways to dispose of the youngest child's stool.

\section{Bivariate analysis of the association between CCP and HAZ}

Bivariate analysis was carried out to examine the associations between CCP and children's nutritional status. The results show a strong positive association between care practices and child HAZ $(\beta=0.12, \mathrm{t}=3.73, \mathrm{p}<0.001)$.

\section{Multivariate analysis of the determinants of children's nutritional status}

The results of the HAZ regression analyses are presented in table 3. The analysis was guided by the framework described earlier and the presentation of results in table 3 follows the framework. In models A and B, both basic and contextual factors were significant predictors of HAZ - maternal age, number of children under 5 years and place of residence were positively associated with HAZ, while child's age was negatively associated with HAZ. Model (C) tested the main effects of resources after controlling for basic and contextual factors. Only maternal weight and WI were significantly associated with HAZ. Model (D) tested for a main effect of CCP, which was a significant predictor of HAZ after adjustment for maternal and child basic factors, context and resources. A 1-unit increase in CCP score was associated with a 0.17-unit increase in HAZ. To establish if some subgroups in the sample benefit more from CCP than others, an interaction analysis was carried out between the CCP variable and child's sex, WI, maternal education, maternal occupation and place of residence. No significant interactions were observed (results not shown).

\section{DISCUSSION}

We examined the influence of CCP on children's HAZ, controlling for covariates and potentially confounding factors at child, maternal, household and community levels as suggested by the UNICEF framework for childcare. We also investigated if care practices were more important to growth in some sociodemographic 
Table 3 Multivariate analysis of determinants of nutritional status of children in Ghana, aged 6-36 months

\begin{tabular}{|c|c|c|c|c|c|c|c|c|}
\hline \multirow[b]{2}{*}{ Variables } & \multicolumn{2}{|l|}{ Model (A) } & \multicolumn{2}{|l|}{ Model (B) } & \multicolumn{2}{|l|}{ Model (C) } & \multicolumn{2}{|l|}{ Model (D) } \\
\hline & Coefficients & t-Statistics & Coefficients & t-Statistics & Coefficients & t-Statistics & Coefficients & t-Statistics \\
\hline \multicolumn{9}{|l|}{ Maternal and child's basic factors } \\
\hline \multicolumn{9}{|l|}{ Child's sex } \\
\hline \multicolumn{9}{|l|}{ Male (ref) } \\
\hline Female & $-0.12(0.10)^{\star}$ & -1.18 & $-0.12(0.10)$ & -1.13 & $-0.08(0.10)$ & -0.77 & $-0.15(0.11)$ & -1.38 \\
\hline Child's age & $-0.24(0.04)$ & $-6.70 \dagger$ & $-0.24(0.04)$ & $-6.48 \dagger$ & $-0.21(0.04)$ & $-5.66 \dagger$ & $-0.25(0.04)$ & $-6.49 \dagger$ \\
\hline Child's age square & $0.005(0.001)$ & $5.67 \dagger$ & $0.005(0.001)$ & $5.47 \dagger$ & $0.004(0.001)$ & $4.66 \dagger$ & $0.005(0.001)$ & $5.02 \dagger$ \\
\hline Maternal age & $0.02(0.01)$ & $2.88 \dagger$ & $0.02(0.01)$ & $2.93 \dagger$ & $0.01(0.01)$ & 0.95 & $0.02(0.01)$ & 1.52 \\
\hline Number of children U5 & $-0.13(0.06)$ & $2.37 \dagger$ & $-0.10(0.06)$ & 1.79 & $-0.11(0.06)$ & -1.89 & $-0.17(0.08)$ & $-2.13 \dagger$ \\
\hline \multicolumn{9}{|l|}{ Contextual factors } \\
\hline \multicolumn{9}{|l|}{ Place of residence } \\
\hline \multicolumn{9}{|l|}{ Urban (ref) } \\
\hline \multirow{2}{*}{\multicolumn{9}{|c|}{ Religion }} \\
\hline & & & & & & & & \\
\hline \multicolumn{9}{|l|}{ Christian (ref) } \\
\hline Other religions & & & $0.21(0.11)$ & 1.85 & $0.17(0.12)$ & 1.36 & $0.10(0.13)$ & 0.81 \\
\hline \multicolumn{9}{|l|}{ Resources } \\
\hline \multicolumn{9}{|l|}{ Maternal resources } \\
\hline Height & & & & & $1.84(0.95)$ & 1.94 & $1.39(0.99)$ & 1.40 \\
\hline Weight & & & & & $0.02(0.01)$ & $2.34 \dagger$ & $0.01(0.01)$ & 1.75 \\
\hline \multicolumn{9}{|l|}{ Anaemia level } \\
\hline \multicolumn{9}{|l|}{ No anaemia (ref) } \\
\hline Some anaemia & & & & & $-0.02(-0.11)$ & -0.22 & $-0.09(0.12)$ & -0.73 \\
\hline Parity & & & & & $0.01(0.04)$ & 0.30 & $0.01(0.05)$ & 0.21 \\
\hline \multirow{2}{*}{\multicolumn{9}{|c|}{$\begin{array}{l}\text { Education and occupation } \\
\text { Secondary+ (ref) }\end{array}$}} \\
\hline \multicolumn{4}{|l|}{ Secondary+ (ref) } & & & & & \\
\hline Education (if primary; 0.1 ) & & & & & $0.14(0.14)$ & 1.04 & $0.01(0.15)$ & 0.07 \\
\hline Education (if no education; 0.1) & & & & & $-0.04(0.16)$ & -0.25 & $-0.08(0.17)$ & -0.45 \\
\hline \multicolumn{9}{|l|}{ White collar (ref) } \\
\hline Agricultural/labour & & & & & $-0.06(0.12)$ & -0.49 & $-0.11(0.14)$ & -0.83 \\
\hline \multicolumn{9}{|l|}{ Empowerment } \\
\hline \multicolumn{9}{|l|}{ Participation in decision-making } \\
\hline High participation (ref) & & & & & & & & \\
\hline Low participation & & & & & $0.14(0.11)$ & 1.27 & $0.06(0.12)$ & 0.54 \\
\hline \multirow{2}{*}{\multicolumn{9}{|c|}{$\begin{array}{l}\text { Husband justified in beating wife } \\
\text { Greater sense of empowerment (ref) }\end{array}$}} \\
\hline & & & & & & & & \\
\hline \multirow{3}{*}{\multicolumn{9}{|c|}{ Wife justified in refusing sex }} \\
\hline & & & & & & & & \\
\hline & & & & & & & & \\
\hline Less empowered & & & & & $0.11(0.16)$ & 0.72 & $0.10(0.16)$ & 0.62 \\
\hline
\end{tabular}




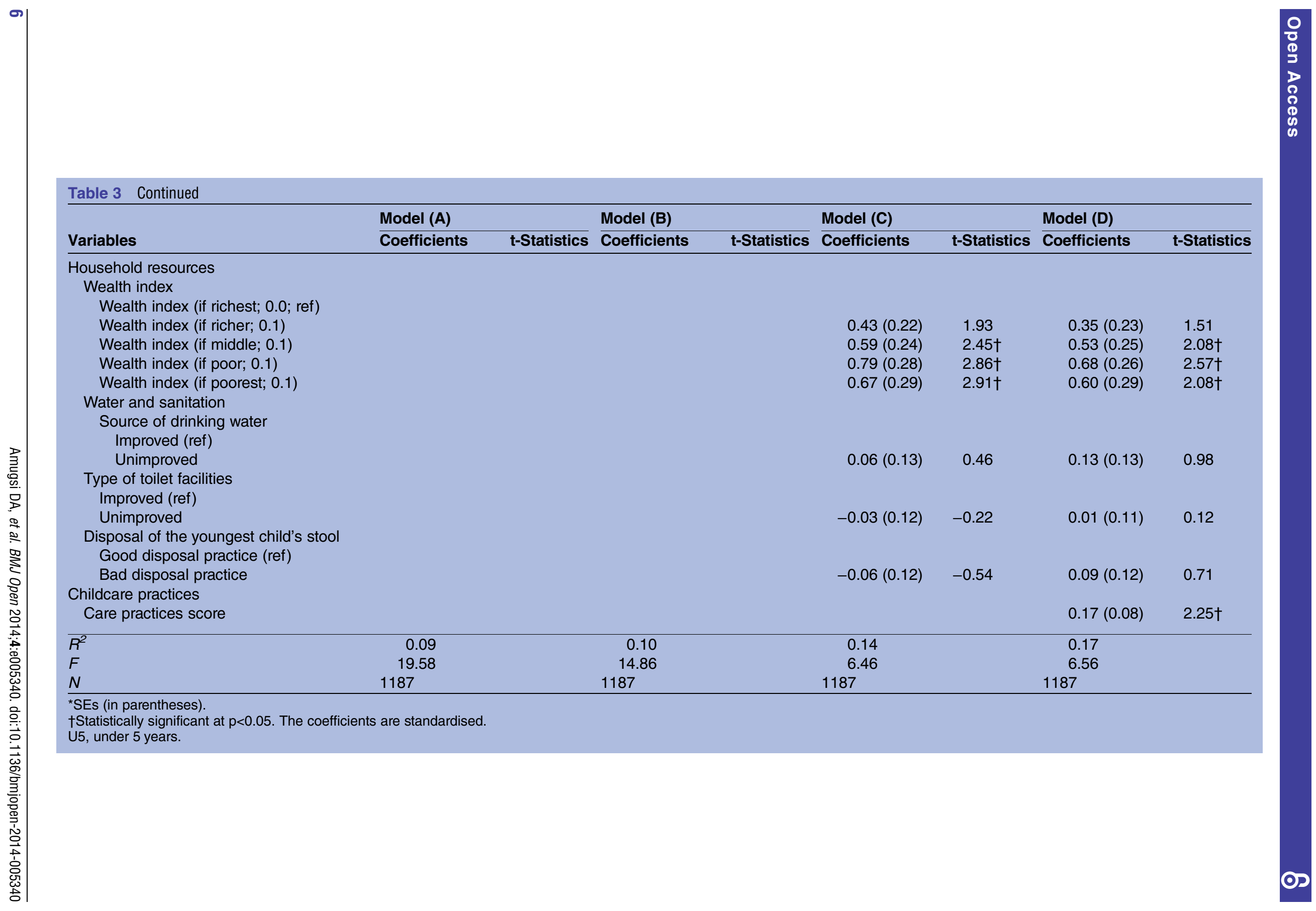

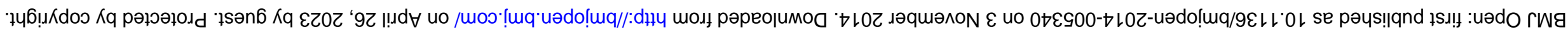


subgroups of children compared with others. Regarding the first aim, we observed a statistically significant relationship between CCP and HAZ, which remained after adjusting for potential confounding factors at child, maternal and household levels. Regarding the second aim, statistical interaction analyses revealed no subgroup differences in the CCP/HAZ relationship.

The finding on the CCP/HAZ relationship is in line with the few previous studies in the literature. Ruel et $a t^{6}$ found that in urban Ghana, good CCP have the potential to mitigate the negative effect of low maternal education and poverty on children nutritional outcomes. A study by Nti and Lartey ${ }^{16}$ in rural Ghana also observed a positive influence of care practices on children's nutritional status. Conversely, both positive and negative effects on nutrition were observed in a study that used a positive deviant methodology to examine the relationship between care practices and children's nutritional status in Bangladeshi children. ${ }^{9}$ With so few studies available on the CCP/children's nutrition relationship, little can be concluded except that in Ghana at least, all three studies examining this issue have come to the same conclusion despite significant methodological variation; CCP is related to children's nutritional status, seemingly regardless of a child's sociodemographic profile.

The above results illuminate the utility of the UNICEF conceptual framework used in this study, both in organising and understanding multilevel factors that impact childcare and growth. This model posits that child growth is not only determined by the availability of adequate nutritious food, but that good care practices and access to health and other social services are equally important. ${ }^{1}{ }^{26}$ This suggests that for optimal child health, these key elements are all highly relevant. As demonstrated by the index used in this study, strategies to improve children's health outcomes should not be limited only to the provision of nutritious food but must also include the promotion of good care practices and access to healthcare. A particular value of using the UNICEF framework in this study was to expand our analytical consideration beyond the most proximal factors connected to child growth.

There is ample literature examining the relationship between some of the components of care practices-such as feeding practices and dietary diversity-and children's nutritional outcomes. Studies in Latin America and Ethiopia using the DHS data observed that good child feeding practices were associated with an improvement in children's nutritional outcomes. ${ }^{14} 27$ Dietary diversity studies have also observed positive associations. ${ }^{11} 28-31$ The present investigation did not decompose CCP to enable analyses of feeding versus non-feeding aspects of childcare, and that is a priority for further analyses. Yet all CCP aspects have face value for one or another facet of child well-being, even if certain aspects of CCP may carry greater weight for child health measured in specific ways.

Statistical interaction analyses did not produce evidence of significant interactions in this sample, suggesting that no subgroup in this population benefited less from good CCP than other subgroups. This is contrary to a study in urban Ghana which revealed that children from poorer households and/or those of mothers with less education were more likely to benefit from better care practices compared with children of wealthier households or those of mothers with better education. ${ }^{6}$ The differences in results could be due to the differences in composition of samples used by both studies. While the present study uses data made up of urban and rural settings, Ruel et al used data from only urban settings. In addition, alternative ways of coding certain predictors (eg, a dichotomised household WI) might have revealed interaction effects that are not evident with the present methodology.

The major strength of this study is the use of highquality nationally representative data to investigate the relationship between CCP and nutritional outcomes. This makes it possible for these findings to be generalised to the whole of Ghana. The additional strength of our study is that we have measured and quantified care practices into a composite score using a nationally representative cross-sectional data. This enables us to examine the impact of care practices collectively on children's nutritional status.

A limitation of this analysis is the inability to disentangle potential reciprocal causation. Our conclusions are therefore carefully restricted to statements about the association between CCP and HAZ, after other variables such as WI are accounted for. WI, CCP and HAZ are interrelated; each may have a causal impact on the other. We have not undertaken to use instrumental variables to gain greater clarity of this matter, but this may be advisable now that the significant association between CCP and HAZ is confirmed. A challenge to move in this direction is the identification of appropriate instrumental variables (those that are associated with CCP but not with HAZ, except for their indirect association via CCP). For example, WI might be used as an instrumental variable under the assumption that its only association with HAZ is via CCP. However, it is equally plausible that WI and HAZ are directly associated, with a family having a low HAZ child using more resources (depleting WI) in order to provide more CCP. It is generally a big challenge to settle on suitable variables in the DHS data for the creation of instruments. The difficulties in using the DHS data to create instrumental variables to address the problem of endogeneity have been documented by previous studies in this area. ${ }^{14}$

Another limitation has to do with the variables used in creating the CCP score. We did have reasonably satisfactory variables available in our data set for home-based care practices and food availability, but the availability of health services and healthy environment variables was less satisfactory. We did not also have a good variable for the measurement of household hygiene. In addition, this study lacked the ability to take into account a host of cultural, sociopolitical and locality factors (local 
contexts) unmeasured by DHS that undoubtedly influence children's health. We cannot reject the possibility that some of such factors account for the observed relationship between CCP and HAZ, in part or in whole.

A limitation that requires comment is the dichotomous treatment of religion, which collapsed all Christian denominations and compared them with all other groups. There are, of course, very important religious affiliation distinctions that might impact health, also within major religious groups such as Christians. In this sample, all these groups were represented: Catholic, Anglican, Methodist, Presbyterian, Pentecostal/Charismatic, Moslem, Traditional/spiritualist, and not religiously affiliated. The decision to cluster religiosity into two groups obfuscated these distinctions, yet preserved some information about religious affiliation. The rationale was that only a qualitative research approach might do justice to the manifold shades of meaning that religiosity might have in connection with childcare in Ghana. We considered avoiding oversimplification by not including data on religion in the analysis, but opted for the suboptimal solution distinguishing Christians from others. We are not aware of any more nuanced approach to the study of religiosity and health in survey research, except perhaps in study designs in which religiosity and health are the main focus; such was not the case in the present investigation.

\section{CONCLUSIONS}

This study found a significant, positive association between CCP and child HAZ, after accounting for other important determinants of child growth at maternal and household levels. Optimising the overall care quality through the inclusion of all components of care practices may be essential to improve children's nutritional status, rather than focusing on the individual components of care. This calls for research into the effects on growth of various CCP components, with longitudinal cohort study designs that can disentangle causal relationships.

Acknowledgements The authors thank MEASURE DHS for releasing the data for this study. We also wish to thank the Ghana Statistical Service and Ghana Health Service who were responsible for collecting the data, and the study participants.

Contributors DAA designed the study, performed the data analysis, interpreted the results and drafted the manuscript. MBM contributed to the study design, data analysis and interpretation and revised the manuscript. AL, HBU and DJM contributed to the data analysis, interpretation and critical revision of the manuscript. All authors read and approved the final version.

Funding This work was supported in part by a scholarship to the DAA from the Norwegian State Educational Loan Fund.

Competing interests None.

Ethics approval Ethical clearance was obtained from the Ghana Health Service Ethical Review Committee.

Provenance and peer review Not commissioned; externally peer reviewed.

Data sharing statement No additional data are available.

Open Access This is an Open Access article distributed in accordance with the Creative Commons Attribution Non Commercial (CC BY-NC 4.0) license, which permits others to distribute, remix, adapt, build upon this work non- commercially, and license their derivative works on different terms, provided the original work is properly cited and the use is non-commercial. See: http:// creativecommons.org/licenses/by-nc/4.0/

\section{REFERENCES}

1. UNICEF (United Nations Children's Fund). Strategy for improved nutrition of children and women in developing countries. UNICEF Policy Review Paper. New York: UNICEF, 1990.

2. CSDH. Closing the gap in a generation: health equity through action on the social determinants of health. Final Report of the Commission on Social Determinants of Health. Geneva: World Health Organization, 2008.

3. Engle P. The role of caring practices and resources for care in child survival, growth, and developments: south and Southeast Asia. Asian Dev Rev 1999;17:132-67.

4. Engle PL. Care and child nutrition: paper prepared for the nutrition section. International Conference on Nutrition (ICN). New York: UNICEF, 1992.

5. World Health Organization, ed. Closing the gap: policy into practice on social determinants of health: discussion paper. WHO, 2011.

6. Ruel MT, Levin CE, Armar-Klemesu M, et al. Good care practices can mitigate the negative effects of poverty and low maternal schooling on children nutritional status: evidence from Accra. World Dev 1999;27:1993-2009.

7. Friedman SL, Amadeo J. The child-care environment: conceptualizations, assessments, and issues. Measuring environment across the life span: emerging methods and concepts. Washington, DC: American Psychological Association, xvii, 419 pp; 1999:127-65.

8. Government of Ghana. National plan of action on food and nutrition 1995-2000. Ghana National Development Planning Commission, 1995.

9. Range SKK, Naved R, Bhattarai S. Child care practices associated with positive and negative nutritional outcomes for children in Bangladesh: a descriptive analysis. Discussion paper. Washington, DC: International Food Policy Research Institute, 1997.

10. Nakahara S, Poudel KC, Lopchan M, et al. Availability of childcare support and nutritional status of children of non-working and working mothers in Urban Nepal. Am J Hum Biol 2006;18:169-81.

11. Arimond M, Ruel MT. Dietary diversity is associated with child nutritional status: evidence from 11 demographic and health surveys. J Nutr 2004;134:2579-85.

12. Bolajoko OO, Ogundahunsi GA. The effect of child care and feeding practices on the nutritional status of children of market women in Ondo State, Nigeria. IOSR J Pharm Bio Sci 2012;1:22-4.

13. Ramji S. Impact of infant and young child feeding and caring practices on nutritional status and health. Indian J Med Res 2009;130:624-6.

14. Ruel MT, Menon P. Child feeding practices are associated with child nutritional status in Latin America: innovative uses of the demographic and health surveys. J Nutr 2002;132:1180-7.

15. Pelto G, Dickin K, Engle P. Promoting healthy growth and development: a review of child development and nutrition interventions. Geneva: WHO, 1999.

16. Nti CA, Lartey A. Influence of care practices on nutritional status of Ghanaian children. Nutr Res Pract 2008;2:93-9.

17. MEASURE DHS. [cited 2014 28.2]. http://www.measuredhs.com/ data/available-datasets.cfm

18. Ghana Statistical Service (GSS), Ghana Health Service (GHS), et al. Demographic and health survey 2008. Accra, Ghana: GSS GHS, and ICF Macro, 2009.

19. Amugsi DA, Mittelmark MB, Lartey A. Dietary diversity is a predictor of acute malnutrition in rural but not in urban settings: evidence from Ghana. Br J Med Med Res 2014;4:4310-24.

20. Tabachnick BG, Fidell LS. Using multivariate statistics. 5th ed. Boston: Allyn \& Bacon, 2007.

21. Field A. Discovering statistics using SPSS. 3rd ed. London: SAGE Publications Ltd, 2009.

22. Pett MA, Lackey NR, Sullivan JJ. Making sense of factor analysis: the use of factor analysis for instrument development in health care research. London: SAGE Publications Ltd, 2003.

23. ESS EduNet (European Social Survey Education Net). Adding non-linearity to OLS regression models [cited 2014 28.2]. http:// essedunet.nsd.uib.no/cms/topics/multilevel/ch1/5.htm

24. WHO/UNICEF. WHO and UNICEF Joint Monitoring Programme (JMP) for water supply and sanitation: types of drinking-water sources and sanitation [cited 2014 28.2]. http://www.wssinfo.org/ definitions-methods/watsan-categories/ 
25. Engle PL, Menon P, Haddadb L. Care and nutrition: concepts and measurements. Washington, DC: International Food Policy Institute, 1997.

26. UNICEF. Improving child nutrition: the achievable imperative for global progress. New York: UNICEF, 2013.

27. Arimond M, Ruel MT. Progress in developing an infant and child feeding index: an example using the Ethiopia Demographic and Health Surveys 2000. Washington, DC: International Food Policy Research Institute, 2002.

28. Ekesa BN, Blomme G, Garming H. Dietary diversity and nutritional status of pre-school children from Musa-dependent households in
Gitega (Burundi) and Butembo (Democratic Republic of Congo). Afr J Food Agriculture Nutr Dev 2011;11:4896-911.

29. Faber M, Smuts CM, Benade AJS. Dietary intake of primary school children in relation to food production in a rural area in

KwaZulu-Natal, South Africa. Int J Food Sci Nutr 1999;50:57-64.

30. Kennedy GL, Pedro MR, Seghieri C, et al. Dietary diversity score is a useful indicator of micronutrient intake in non-breast-feeding Filipino children. J Nutr 2007;137:472-7.

31. Mishra V, Ray R. Dietary diversity, food security and undernourishment: the Vietnamese evidence. Asian Econ $J$ 2009;23:225-47. 